resolve with this approach than with the hit-and-miss methods that are usually adopted.

1 Department of Health and Social Security. Digest of health statistics. London: HMSO, 1971.

${ }^{2}$ Bridger RC. Sinusitis: an improved regime of investigation for the clinical laboratory. $\mathcal{F}$ Clin Pathol 1980;33:276-81.

${ }^{3}$ Lystad A, Berdal P, Lund-Iversen L. The bacterial flora of sinusitis with an in vitro study of the bacterial resistance to antibiotics. Acta Otolaryngol (Stockh) 1964;188, suppl:390-9.

4 Smith JM, Smith IM. The medical treatment of sinusitis. Otolaryngol Clin North Am 1971;4:39-55.

5 Dawes JDK. Chemotherapy in infections of the ear, nose and throat. Practitioner 1971 ;207:735-42.

- Sparrevohn UR, Buch A. The bacteriology of maxillary sinusitis. Acta Otolaryngol (Stockh) 1946;34:425-36.

${ }^{7}$ Frederick J, Braude AI. Anaerobic infection of the paranasal sinuses. N Engl f Med 1974;290:135-7.

\section{The risks of assessing risks}

No scientific or technological activity can be completely free from risk. If we want to be able to use electricity, take drugs when we are ill, and travel by car or plane then people are going to die and be injured as a result. Though risks cannot be totally eradicated, they can be measured, investigated, evaluated, controlled, and reduced; and these studies-and how the public perceives risks-were the subjects of a twoday conference at the Royal Society last week.

Why have scientists begun to measure risks? Probably because people's attitudes to misfortune have changed: fatalism has faded, and when a disaster occurs people now look for a cause and a scapegoat. As Dr P G Harvey of Imperial Chemical Industries said: "This is the first generation that feels it is entitled to immortality." Often the public have blamed industry and technology for misfortune; applied science and scientists themselves have become suspect; and, as Professor D Pearce of Aberdeen suggested, "risk analysis has appeared as a defence against these accusations."

Much of the conference was devoted to methods of measuring risk, which all agreed was extremely difficult. Ultimately, the magnitude of any misfortune was a subjective judgment. The social importance of an undesired event, the number of people affected, and the probability of it happening all had to be quantified. Was the death of an infant equivalent to the death of an 80-year-old? Was death by fire equivalent to death by lung cancer? Most speakers agreed that any analysis that treated all deaths as equivalent was worthless. Repeatedly the conference returned to this theme that the way the public viewed risks, which might be "irrational," was just as important as the way that experts measured them. Experts' and the public's assessments were seen as "different but complementary."

The second problem in measuring risks was that in almost all cases the data were limited and unreliable. Even mortality data related to social class and occupation, a risk measure familiar to most doctors, need to be intepreted with the greatest caution. Yet at least death was an easily defined event and there was a great deal of past experience to predict from. With many risk analyses there was no such past experience-the prime example being a core meltdown in a nuclear reactor. With new drugs, too, there were formidable problems in predicting and measuring risks. Increasingly refined toxicological studies in animals permitted better analyses, but unexpected side effects would always be seen when the drugs were first used in man. Even if they existed past data might be very sparse. Professor E D Acheson from Southampton explained that to predict the risk from an environmental carcinogen the dose-response curve and the exposure of individuals had to be known; yet for only four environmental carcinogens-cigarettes, alcohol, asbestos, and ionising radiation-was there enough information. "No human data are better than indifferent data," he dolefully concluded. A further problem with measuring risk was assessing the human factor. Men ignored instructions, dropped spanners into important works, and slept through alarms, and sometimes they would deliberately abuse and sabotage.

Once risks have been measured they must be evaluated. With this problem in mind several psychologists spoke at the conference. Undoubtedly a gap exists between the measurements of scientists and the perceptions of the public: evidence was presented that the public regard nuclear power as particularly risky while the experts regard it as relatively safe compared with other forms of energy production. The factors that affect subjective assessment of risk were subtle and complicated, but among those mentioned were whether a risk was voluntary; whether a hazard was familiar; whether the risk was to an individual or to a whole community; the cause of a hazard; and the size of a catastrophe. Several speakers pointed out that looking back on changes in legislation, large and spectacular catastrophes-for instance, Aberfan and Flixborough-have had a strong effect.

How could risk assessments be used? They can be used to reduce risks-industrial accidents are declining at a rate of about $5 \%$ a decade. Secondly, they permit intelligent choices between different technologies; this is, perhaps, most important in relation to energy production. Thirdly, regulatory bodies may soon begin to specify numerically what is an acceptable risk-but how they will decide what is acceptable remains problematical. Risk assessment, no matter how refined it became, can be only one tool in decision making.

\section{Alzheimer's disease}

Dementia is one of the greatest problems facing modern society, and yet one that seems little appreciated. The condition affects one person in every six over the age of $65 .{ }^{12}$ Those affected survive only one-third as long as healthy people of the same age and sex, but dementia greatly taxes the family and the medical and nursing professions-and, indeed, is a severe burden on the economy.

The most common cause of dementia is Alzheimer's disease. Postmortem examination of patients with dementia shows its characteristic features in half of all cases; multi-infarct dementia accounts for $20 \%$, and in a further $20 \%$ these two disorders are present together. ${ }^{3}$ Inherited metabolic abnormalities, chronic alcoholism, and other causes account for the remainder. Treatable causes of dementia such as normalpressure hydrocephalus, vitamin deficiencies, and metabolic disorders form a very small proportion of the total.

Alzheimer's disease may be readily diagnosed clinically in most cases, and the division into presenile and senile forms is no longer thought worth while. The typical patient preserves his personality in the early stages but shows an inability to learn new material and short-term memory loss. Many patients are also depressed. The diagnosis is confirmed histologically by the presence of senile plaques, neurofibrillary 
tangles, granulovacuolar degeneration, and congophilic angiopathy. A correlation has been shown between the degree of dementia and the number of senile plaques. ${ }^{4}$

These senile plaques consist of a dense core of extracellular amyloid, surrounded by mitochondria, lysosomes, and axonal boutons. Affected areas show increased oxidative and hydrolase activity. ${ }^{2}$ Immunoglobulins have been shown to be associated with amyloid in the senile plaques. ${ }^{5}$ The cells concerned may be macrophages or microglia or both: such cells are invariably found with the amyloid that is detectable in the brains of aged dogs. ${ }^{6}$ The congophilic angiopathy is due to amyloid in the subendothelial layer of cerebral capillaries and in the intima and media of cerebral arteries and veins; the source of the amyloid is probably the serum. ${ }^{7}$

Myeloproliferative disorders are more common than would be expected in first-degree relatives of patients with Alzheimer's disease ${ }^{8}$; this may be due to a primary or secondary abnormality of the microtubules dealing with cell division. No definite association has been found between Alzheimer's disease and any of the major histocompatibility haplotypes. No lymphocyte abnormalities have been found after comparison with controls matched for age and sex. Serum antibodies against neurones have been identified, but in detailed studies done in Glasgow and London these antibodies have also been shown in patients with other conditions ( $H$ Watts, P Kennedy, M A Thomas, paper in preparation). Studies on cerebral concentrations of aluminium and silicon have yielded conflicting results, but there is some evidence of an increase in patients with the disease. ${ }^{9}$ No virus has been isolated or transmitted from patients, but one important discovery has been that senile plaques appear in specific strains of aged mice when they are infected with certain scrapie agents. ${ }^{1011}$

Disturbances in the metabolism of neurotransmitters have been widely reported, affecting in particular the cholinergic system and resulting in depletion of choline acetyltransferase and acetylcholine esterase. ${ }^{1213}$ These findings suggest that there is either loss of cholinergic cells or degeneration of cholinergic terminals. In clinical studies in which patients were given choline or choline-containing substances, however, these agents were ineffective in improving or halting progression of the illness. Recently a far wider disturbance of neurotransmitter systems has been postulated, with the dopamine, gamma-aminobutyric acid, and noradrenergic systems all affected. ${ }^{14} 15$

Despite the plethora of hypotheses, however, objective analysis of all the data-immunological, genetic, virological, pathological, and biochemical-shows that we still have no idea of the aetiology of Alzheimer's disease.

${ }^{1}$ Katzman $\mathbf{R}$. The prevalence and malignancy of Alzheimer's disease: a major disease. Arch Neurol 1976;33:217-8.

2 Terry RD. Dementia: a brief and selective review. Arch Neurol 1976;33: 1-4.

${ }^{3}$ Butler RN. In : Katzman R, Terry RD, Bick KL, eds. Alzheimer's disease: senile dementia and related disorders. (Aging. Vol 7.) New York: Raven Press, 1978.

- Blessed G, Tomlinson BE, Roth M. The association between quantitative measures of dementia and of senile change in the cerebral grey matter of elderly subjects. Br F Psychiatry 1968;114:797-811.

5 Ishii T, Haga S. Immuno-electron microscopic localization of immunoglobulins in amyloid fibrils of senile plaques. Acta Neuropathol (Berl) $1976 ; 36: 243-9$.

- Wisniewski H, Johnson AB, Raine CS, Kay WJ, Terry RD. Senile plaques and cerebral amyloidosis in aged dogs. A histochemical and ultrastructural study. Lab Invest 1970;23:287-96.

7 Glenner GG. Current knowledge of amyloid deposits as applied to senile plaques and congophilic angiography. In: Katzman R, Terry RD, Bick $\mathrm{KL}$, eds. Alzheimer's disease: senile dementia and related disorders. (Aging. Vol 7.) New York: Raven Press, 1978.

8 Heston LL. Alzheimer's disease, trisomy 21, and myeloproliferative disorders: associations suggesting a genetic diathesis. Science 1977;196: 322-3.
${ }^{9}$ Perl DP, Brody AR. Alzheimer's disease: $x$-ray spectrometric evidence of aluminium accumulation in neurofibrillary tangle-bearing neurons. Science 1980;208:297-9.

${ }^{10}$ Fraser H, Bruce ME. Argyrophilic plaques in mice inoculated with scrapie from particular sources. Lancet 1973;i:617-8.

${ }^{11}$ Bruce ME, Dickinson AG, Fraser H. Cerebral amyloidosis in scrapie in the mouse: effect of agent strain and mouse genotype. Neuropathology and Applied Neurobiology 1976;2:471-8.

12 Bowen DM, Smith CB, White P, Davison AN. Neurotransmitter-related enzymes and indices of hypoxia in senile dementia and other abiotrophies. Brain 1976;99:459-96.

13 Davies P, Maloney AJF. Selective loss of central cholinergic neurone in Alzheimer's disease. Lancet 1976;ii:1403.

${ }^{14}$ Reisine TD, Yamamura HI, Bird ED, Spokes E, Enna SJ. Pre- and postsynaptic neurochemical alterations in Alzheimer's disease. Brain Res 1978;159:477-81.

${ }^{15}$ Mann DMA, Lincoln J, Yates PO, Stamp JE, Toper S. Changes in the monamine containing neurones of the human $\mathrm{CNS}$ in senile dementia. BrF Psychiatry 1980;136:533-41.

\section{Audit in general practice}

Whoever coined the phrase medical audit has a lot to answer for. In everyday speech, auditors are cold, authoritarian figures who visit an organisation to detect fraud, incompetence, or inefficiency and report back to some central organisation. In medical practice, audit is a self-monitoring procedure carried out by doctors on their own work and reported only to the participants. Yet the authoritarian image persists and was present, like Banquo's ghost, for much of the day at the conference last week at BMA House on medical audit in general practice ( $p$ 1440). If nothing else resulted from that meeting, it should finally have stilled any fears among GPs that the BMA's General Medical Services Committee or the Royal College of General Practitioners, who jointly organised the occasion, had any plans for a corps of inspectors.

Like many new concepts in medicine, audit has not always been helped by the efforts of its enthusiasts to convince the doubters. Talk of process and outcome and of a whole plethora of abstract concepts clouds the simplicity of the idea: that doctors should look at their daily work to see if they can improve it. The examples described at the conference were everyday problems. Are all the home visits by the practice nurses necessary ? How helpful are midstream urine examinations in treating urinary infections ? Could the care of epileptic patients be improved? In such cases the doctors in a group practice can learn an enormous amount by recording exactly what they do, comparing their actual practice with what they thought they did, and deciding after discussion among themselves what they will do in future. The crucial step, however, is the final one: repeating the exercise after an interval to see whether the good intentions have actually been carried through.

What the advocates of audit now need to do is to convince the sceptics and the silent, indifferent majority that the effort is worth while. Many innovations in general practice are intellectually stimulating but make little difference to the quality of care provided to patients. Do auditing procedures have longlasting effects-and how can these be measured? The evidence so far is very persuasive. The enthusiasts should recognise, however, that many general practitioners will want to move at their own pace-as they did in adopting ideas such as health centres and group practice premises, attached nurses, appointment systems, and deputising services. These have come into the mainstream of general practice because the majority became convinced that they were cost effective and of real practical value. If medical audit passes the same pragmatic tests it, too, will become routine within a generation. 